\title{
Krill population dynamics at South Georgia: implications for ecosystem-based fisheries management
}

\author{
Keith Reid ${ }^{1,2}$, Jon L. Watkins ${ }^{1, *}$, Eugene J. Murphy ${ }^{1}$, Phil N. Trathan ${ }^{1}$, \\ Sophie Fielding ${ }^{1}$, Peter Enderlein ${ }^{1}$
}

\author{
${ }^{1}$ British Antarctic Survey, Natural Environment Research Council, High Cross, Madingley Road, Cambridge CB3 0ET, UK \\ ${ }^{2}$ Present address: Commission for the Conservation of Antarctic Marine Living Resources, PO Box 213, North Hobart, \\ Tasmania 7002, Australia
}

\begin{abstract}
The South Georgia region supports a large biomass of krill that is subject to high interannual variability. The apparent lack of a locally self-maintaining krill population at South Georgia means that understanding the mechanism underlying these observed population characteristics is essential to successful ecosystem-based management of krill fishery in the region. Krill acoustic-density data from surveys conducted in the early, middle and late period of the summers of 2001 to 2005 , together with krill population size structure over the same period from predator diet data, were used with a krill population dynamics model to evaluate potential mechanisms behind the observed changes in krill biomass. Krill abundance was highest during the middle of the summer in 3 years and in the late period in 2 years; in the latter there was evidence that krill recruitment was delayed by several months. A model scenario that included empirically derived estimates of both the magnitude and timing of recruitment in each year showed the greatest correlation with the acoustic series. The results are consistent with a krill population with allochthonous recruitment entering a retained adult population; i.e. oceanic transport of adult krill does not appear to be the major factor determining the dynamics of the adult population. The results highlight the importance of the timing of recruitment, especially where this could introduce a mismatch between the peak of krill abundance and the peak demand from predators, which may exacerbate the effects of changes in krill populations arising from commercial harvesting and/or climate change.
\end{abstract}

KEY WORDS: South Georgia • Antarctic krill • Euphausia superba • Population dynamics · Recruitment $\cdot$ Match-mismatch

Resale or republication not permitted without written consent of the publisher

\section{INTRODUCTION}

Marine ecosystems are inherently variable at scales ranging from processes associated with single organisms to those arising from large-scale climate forcing that impact entire ocean systems over multiple years (Murphy et al. 1988, Chavez et al. 2003, Greenberg et al. 2007). Despite the large difference in the scales involved, many analyses of variability in marine ecosystems rely on annual indices, often derived over a limited period of time, that provide proxies for a range of ecosystem processes. Such indices can provide very useful indicators of the status of key components of the ecosystem and may often reveal the underlying processes driving variability. However, where the timing of annual sampling is fixed, i.e. there is an assumption of fixed intra-annual chronology, there is the potential for apparent inter-annual variability to be an artefact of changes in that intra-annual chronology. In highlatitude marine systems that are characterised by a high degree of seasonality, the potential for shifts in chronology of key events within a year have a high potential to bias measures that are intended to provide indices at an annual scale.

In the Southern Ocean, Antarctic krill Euphausia superba is the dominant mid-trophic-level species, and 
variability in its abundance and distribution, which are linked with large-scale physical processes (Murphy et al. 2007b), have a profound impact on the performance of a range of upper-trophic level species including fish, penguins and whales (Croxall et al. 1988, 1999, Leaper et al. 2006). In most studies of the nature and extent of this variability, indices of the abundance of krill have been presented at annual scales (Brierley et al. 1999, Hewitt et al. 2003). However, at South Georgia, an area of particularly high krill abundance (Atkinson et al. 2004), there is considerable evidence for intraannual variability in the size-structure of krill at the scale of weeks to months (Reid et al. 1999) and for krill biomass at the scale of months (Brierley et al. 2002). In addition there is evidence for changes in krill sizestructure associated with changes in biomass at an annual scale (Murphy \& Reid 2001). Therefore there is a need to understand the relationship between point samples used to produce annual indices of abundance and the underlying, continuously fluctuating population from which those indices are drawn.

Understanding the population dynamics of krill at South Georgia is of considerable importance in the context of resources management given the uncertainty surrounding the mechanisms that maintain the high biomass of krill at South Georgia (see Nicol 2006). It is generally considered that krill do not form a selfmaintaining population at South Georgia, since larvae are found too infrequently for this to be the case (Tarling et al. 2007). There is considerable evidence of oceanic transport of krill into the South Georgia region (Murphy et al. 2004). However, uncertainties as to the exact role of this transport have led to differing views of how the krill population at South Georgia is maintained. One view is of a quasi-continuous flow of krill, comprised of all age-classes, passing the island with little or no local retention, at least not on a multi-year scale, contrasting with the view in which there is allochthonous recruitment, arriving by oceanic transport, that joins an adult population that is then retained in the area for periods of several years (see Reid et al. 2002). Based on annual measures of krill population size and structure it may be not be possible to distinguish between these 2 views of the system.

Although both of the scenarios described in the previous paragraph could present the dependent species such as penguins and seals with large concentrations of krill upon which to feed, the implications for fisheries management arising from them could be quite different. In a situation where the krill population is continually replenished by input from ocean currents, the ability of a local fishery to impact either the local krill population, and hence dependent predators, would be relatively low compared to a situation where fishing takes place on a locally retained population that is the product of annual recruitment and in situ growth. Addressing this 'structural uncertainty' about how the krill population at South Georgia is maintained is crucial to avoiding fisheries-management decisions that may have an adverse impact on the exploited stock and trophically related species.

The existing focus on krill dynamics at an annual scale has been determined to a large extent by the availability of data (indeed collecting consistent series of annual data for such analyses is not straightforward in this region). Nevertheless it has become apparent, particularly through data from the diet of krill predators, that there is considerable intra-annual variation in the population size structure of krill, associated with changes in abundance, at sub-annual time scales. Until recently there has been no ship-based survey data with which to assess these intra-annual changes in krill abundance in the context of apparent inter-annual variability (but see Saunders et al. 2007).

The aim of the present study was to use acoustic data on krill density collected in a study area to the NW of South Georgia during the early, middle and late parts of the summer over a $5 \mathrm{yr}$ period in order to examine variability in krill abundance at both intraand inter-annual scales. The population size structure of krill in the survey area over the same time period was assessed using krill in the diet of Antarctic fur seals Arctocephalus gazella that were collected from Bird Island, South Georgia. Antarctic fur seals breeding at this site are known to forage in the same area as the krill survey was conducted and these samples provide a consistent record of the changes in the sizestructure of the krill population over the period of the present study (Boyd et al. 2002). In order to simulate different scenarios of krill population dynamics, a flexible krill population dynamics model was developed to evaluate the potential mechanisms that could produce the changes in krill biomass measured in the surveys.

\section{MATERIALS AND METHODS}

Krill biomass estimates. Acoustic surveys were conducted annually during the early (October and November), middle (January and February) and late (March to May) period of each year between October 2000 and March 2005 at the NW end of South Georgia. The survey design for this 'Western Core Box' region consists of eight $80 \mathrm{~km}$ randomised parallel transects covering a total survey area of $10664 \mathrm{~km}^{2}$ (see Brierley et al. 2002 for further details of rationale). Two transects were typically run per day during daylight hours with the total survey usually being completed in $4 \mathrm{~d}$ subject to weather and logistical constraints. 
The acoustic survey data were collected initially using a Simrad EK500 echosounder with hull-mounted transducers operating at 38, 120 and $200 \mathrm{kHz}$ between October 2000 and May 2002. In 2002 the Simrad EK500 was replaced with a Simrad EK60 echosounder operating at the same frequencies. Both echosounders were calibrated annually at South Georgia using a standard sphere technique (following Foote et al. 1987). The annual calibration was applied to all cruises within that season with the exception of the calibration for 2005. In 2005, the $120 \mathrm{kHz}$ calibration values for target strength (TS) gain and area backscattering strength (Sa) correction of 20.05 and $0.19 \mathrm{~dB}$ respectively were substantially lower than previous and subsequent calibrations (2004 values were 21.25 and $0.02 \mathrm{~dB}$ while 2006 values were 21.37 and $-0.03 \mathrm{~dB}$ ) and so the value for 2004 was used. Given the long-term stability of the $120 \mathrm{kHz}$ transducer (British Antarctic Survey unpubl. data), this is not considered to have biased the results of the present study.

Acoustic data were collected every $2.5 \mathrm{~s}$ along the transects at a nominal survey speed of 10 knots and logged with Sonardata Echolog software (Version 4.2, Myriax Software, www.echoview.com). Post-cruise data processing was carried out using Sonardata Echoview to apply survey-derived values of absorption coefficient, sound velocity and calibration corrections, to remove any noise and bad data and to average data into $500 \mathrm{~m}$ horizontal by $5 \mathrm{~m}$ vertical bins. Krill were identified using the $\mathrm{dB}$ difference between 120 and $38 \mathrm{kHz}$ of between 2 and $12 \mathrm{~dB}$ (Watkins \& Brierley 2002). Krill biomass was calculated using the methods developed for the CCAMLR 2000 Survey (Hewitt et al. 2004) converting echo energy to areal density $\left(\mathrm{g} \mathrm{m}^{-2}\right)$ using the target strength model of Greene et al. (1991). Target strength (TS) for each survey was calculated in $\mathrm{dB} \mathrm{kg}{ }^{-1}$ on the basis of the mean length of krill caught in RMT8 nets during the mid-season survey or derived from the length of krill in the diet of Antarctic fur seals at Bird Island (Brierley et al. 2002) for all other surveys. Transect-specific krill densities were averaged within survey areas to determine weighted mean krill densities and weighted variances after Jolly \& Hampton (1990a). The start dates and krill biomass estimates for each survey are given in Table 1.

Krill population size structure. The lengthfrequency distribution of krill in the survey area was estimated using the length-frequency distribution of krill in the diet of Antarctic fur seals at Bird Island, South Georgia following the methods of Reid et al. (1999). These length-frequency distributions were produced to coincide with the early (November), middle (December and January) and late (February and March) parts of the summer. An estimate of proportional recruitment $\beta$ was estimated for each year as the
Table 1. Krill density estimates from ship-based acoustic surveys at South Georgia, 2001 to 2005. CV\%: coefficient of variation

\begin{tabular}{|ccccc|}
\hline Year & Period & $\begin{array}{c}\text { Start date } \\
(\mathrm{d} / \mathrm{mo} / \mathrm{yr})\end{array}$ & $\begin{array}{c}\text { Mean density } \\
\left(\mathrm{g} \mathrm{m}^{-2}\right)\end{array}$ & $\mathrm{CV} \%$ \\
\hline 2001 & Early & $29 / 10 / 00$ & 3.5 & 65.6 \\
2001 & Middle & $03 / 01 / 01$ & 34.7 & 30.7 \\
2001 & Late & $18 / 03 / 01$ & 6.5 & 31.1 \\
2002 & Early & $03 / 11 / 01$ & 3.8 & 39.0 \\
2002 & Middle & $14 / 01 / 02$ & 41.8 & 44.9 \\
2002 & Middle & $25 / 01 / 02$ & 66.6 & 33.9 \\
2002 & Late & $12 / 05 / 02$ & 8.6 & 36.1 \\
2003 & Early & $16 / 10 / 02$ & 19.7 & 50.5 \\
2003 & Middle & $14 / 02 / 03$ & 36.2 & 52.9 \\
2003 & Late & $28 / 04 / 03$ & 70.6 & 38.9 \\
2004 & Early & $14 / 11 / 03$ & 3.1 & 32.2 \\
2004 & Middle & $09 / 01 / 04$ & 11.1 & 14.2 \\
2004 & Late & $28 / 03 / 04$ & 34.6 & 67.3 \\
2005 & Early & $22 / 11 / 04$ & 19.0 & 37.5 \\
2005 & Middle & $07 / 01 / 05$ & 32.1 & 49.0 \\
2005 & Late & $31 / 03 / 05$ & 12.2 & 33.1 \\
\hline
\end{tabular}

proportion of krill $<46 \mathrm{~mm}$ in the late-season lengthfrequency distribution, and the timing of recruitment was estimated on the basis of the presence of the $46 \mathrm{~mm}$ mode in both the middle and the late periods (indicating early recruitment) or where this mode was only in the late period (indicating late recruitment) (see Table 2).

Krill population model. For each age class a in time period $t$ of year $y$ the number of individuals in class $a$ at $t=1$ was

$$
\begin{aligned}
& N_{(1, y, 1)}=R_{(y, 1)} \\
& N_{(a, y, 1)}=N_{\left(a, y-1, t_{(\max )}\right)} \mathrm{e}^{-\left(M+P_{(a, t)}\right)}+R_{(y, 1)}
\end{aligned}
$$

When $t>1$ the number of individuals was

$$
N_{(a, y, t)}=N_{(a, y, t-1)} \mathrm{e}^{-\left(M+P_{(a, t)}\right)}+R_{(y, t)}
$$

where $M$ is the rate of natural mortality and $P_{(a, t)}$ is the predator-induced mortality of age class $a$, following the selectivity ogive described by Murphy \& Reid (2001), at time $t$, where

$$
P_{(t)}=P z_{(t)}
$$

Table 2. Proportional recruitment $\beta$ and recruitment timing $\gamma$ for krill at South Georgia from 2001 to 2005

\begin{tabular}{|ccc|}
\hline Year & $\beta$ & $\gamma$ \\
\hline 2001 & 0.44 & Early \\
2002 & 0.43 & Early \\
2003 & 0.33 & Late \\
2004 & 0.21 & Late \\
2005 & 0.11 & Early \\
\hline
\end{tabular}


in which the parameter $\mathrm{z}_{(t)}$ is a vector that describes the variation in timing of predator-induced mortality through the year.

To produce an index of the numbers of recruits in each year, $R_{(\mathrm{y})}$, the mean number of recruits that maintained a stable population over a $1000 \mathrm{yr}$ run of the model $(\bar{E})$ was estimated. This was then scaled by the ratio of the annual proportional recruitment index $\beta_{(y)}$ to the mean proportional recruitment index such that

$$
R_{(y)}=\bar{E} \frac{\beta_{(y)}}{\bar{\beta}}
$$

where

$$
\bar{\beta}=\left(\frac{\sum_{y=1}^{n} \beta_{(y)}}{n}\right)
$$

In addition to a variable number of recruits in each year, the model was designed to allow flexibility in the timing of recruitment within the year such that the number of recruits entering the population in time period $t$ was

$$
R_{(y, t)}=R_{(y)} \gamma_{(t)} \mathrm{e}^{-(M)}
$$

where $\gamma_{(\mathrm{t})}$ is the proportion of $R_{(\mathrm{y})}$ entering the population in time period $t$; pre-recruits were exposed to natural mortality but not to predator-induced mortality.

The value of $\gamma$ was chosen from a pre-defined vector for each run of the model depending on whether recruitment was early or late.

The biomass in time period $t$ of year $y$ was

$$
B_{(y, t)}=\sum_{a=1}^{7} N_{(a, y, t)} \omega_{(a, t)}
$$

where $\omega$ is mass of an individual krill of age $a$ at time $t$ where

$$
\omega_{(a, t)}=\left\{\begin{array}{cc}
1_{\infty}\left[1-\mathrm{e}^{(-k(a+(4 t / 360))}\right]^{3} ; & 0<t \leq 90 \\
\omega_{(a, t-1)} & : t \geq 91
\end{array}\right.
$$

assuming that growth occurs for the first $90 \mathrm{~d}$ of the year $(360 \mathrm{~d})$ and $l_{\infty}$ and $k$ are constants. All constants used in the model are given in Table 3.

Krill population simulation. For the purposes of simulation the model was run for $5 \mathrm{yr}$ under each of the following 4 scenarios based on the observed changes in population size structure:

(1) $R$ fixed as the mean recruitment $(\bar{E})$ from the long-term model run and $\gamma$ early in each year;

(2) $R$ varied according to Eq. (4) using the values for $\beta$ in Table 2 with $\gamma$ early in each year;

(3) $R$ fixed as in Scenario 1 and $\gamma$ representing either early or late recruitment according to the values in Table 2;

(4) $R$ varied as in Scenario 2 and $\gamma_{(\mathrm{t})}$ varied as in Scenario 3.

For each scenario a simulated survey time-series of biomasses was produced by extracting the biomass estimates that occurred nearest to the sampling date of each research cruise. The relationship between the simulated series and the empirical time-series from the surveys was then compared.

\section{RESULTS}

\section{Krill population size structure}

In all years the early-season length-frequency distribution was dominated by a modal size class of 46 to

Table 3. Parameters used in the krill model

\begin{tabular}{|llcl|}
\hline Parameter & Description & Value & Rationale or source \\
\hline$t$ & Time step (d) & 20 & \\
$t_{0}$ & Start date for model & 1 November & $\begin{array}{l}\text { Onset of krill growth period and predator } \\
\text { breeding season }\end{array}$ \\
$I_{\infty}$ & Max. size of krill & $60 \mathrm{~mm}$ & Following Murphy \& Reid (2001) \\
$k$ & Growth rate constant & 0.7 & Reid (2001) \\
$M$ & Natural mortality rate & 0.6 & Murphy \& Reid (2001) \\
$P$ & Predator-induced mortality rate & 1.5 & Murphy \& Reid (2001) \\
$z$ & Period of predator-induced mortality & Days $0-150$ & Approximate period of predator breeding season \\
$\gamma_{(t)}$ & Recruitment timing & & Timings indicative of recruitment happening over \\
& 'Early recruitment' & $\gamma_{(0)}=0.2$ & time either early or late in the summer \\
& & $\gamma_{(20)}=0.6$ & \\
& 'Late recruitment' & $\gamma_{(40)}=0.2$ & \\
& & $\gamma_{(120)}=0.2$ & \\
& $\gamma_{(140)}=0.6$ & \\
& $\gamma_{(180)}=0.2$ & \\
\hline
\end{tabular}


$48 \mathrm{~mm}$; this size class formed the dominant mode in all periods of 2001 and 2002, in the early and late periods only in 2003 and 2004 and during the early period only in 2005 (Fig. 1).

\section{Krill biomass}

There was considerable variability both within and between years in the biomass estimates and their associated coefficient of variation (CV\%) (Table 1). As noted by Jolly \& Hampton (1990b) and seen in other analyses of krill acoustic data (Reiss et al. 2008), the highest CV\% values (those surveys where CV\% > 50) will result in a negative lower confidence interval. An analysis of variance (ANOVA) using all surveys classified by year indicated that the within-year variability was greater than the inter-annual differences (1-way ANOVA: $F_{4,11}=0.81, \mathrm{p}=0.542$ ). There were 3 years (2001, 2002 and 2005) in which the mid-season esti- mate was the highest for that year; in the other 2 years $(2003,2004)$ it was the late-season estimate that was the highest.

\section{Krill population model}

In Scenario 1, with fixed recruitment number and timing, there was a consistent pattern of low-highlow biomass in the early, middle and late periods respectively, which was replicated in the simulated time-series (Fig. 2a,b). In Scenario 2 the magnitude of the mid-season increase varied according to the level of recruitment but the intra-annual pattern with respect to the early and later periods was maintained (Fig. 2c,d). In Scenario 3 those years in which recruitment occurred early showed the same pattern of biomass change as the previous scenarios, whereas in those years when recruitment was late there was a bimodality in the biomass during the course of the
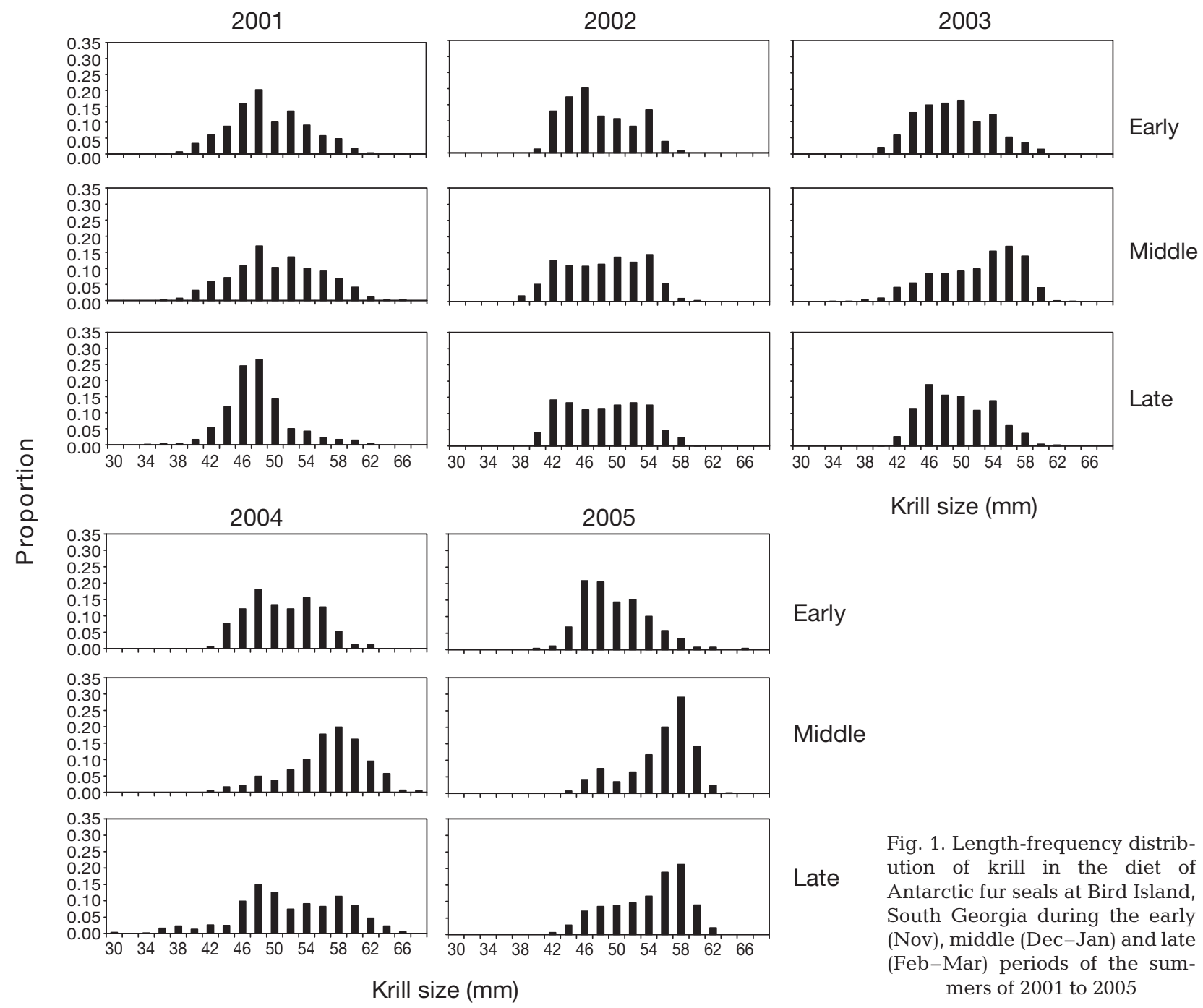

Middle

Late

Fig. 1. Length-frequency distribution of krill in the diet of Antarctic fur seals at Bird Island, South Georgia during the early (Nov), middle (Dec-Jan) and late (Feb-Mar) periods of the summers of 2001 to 2005 


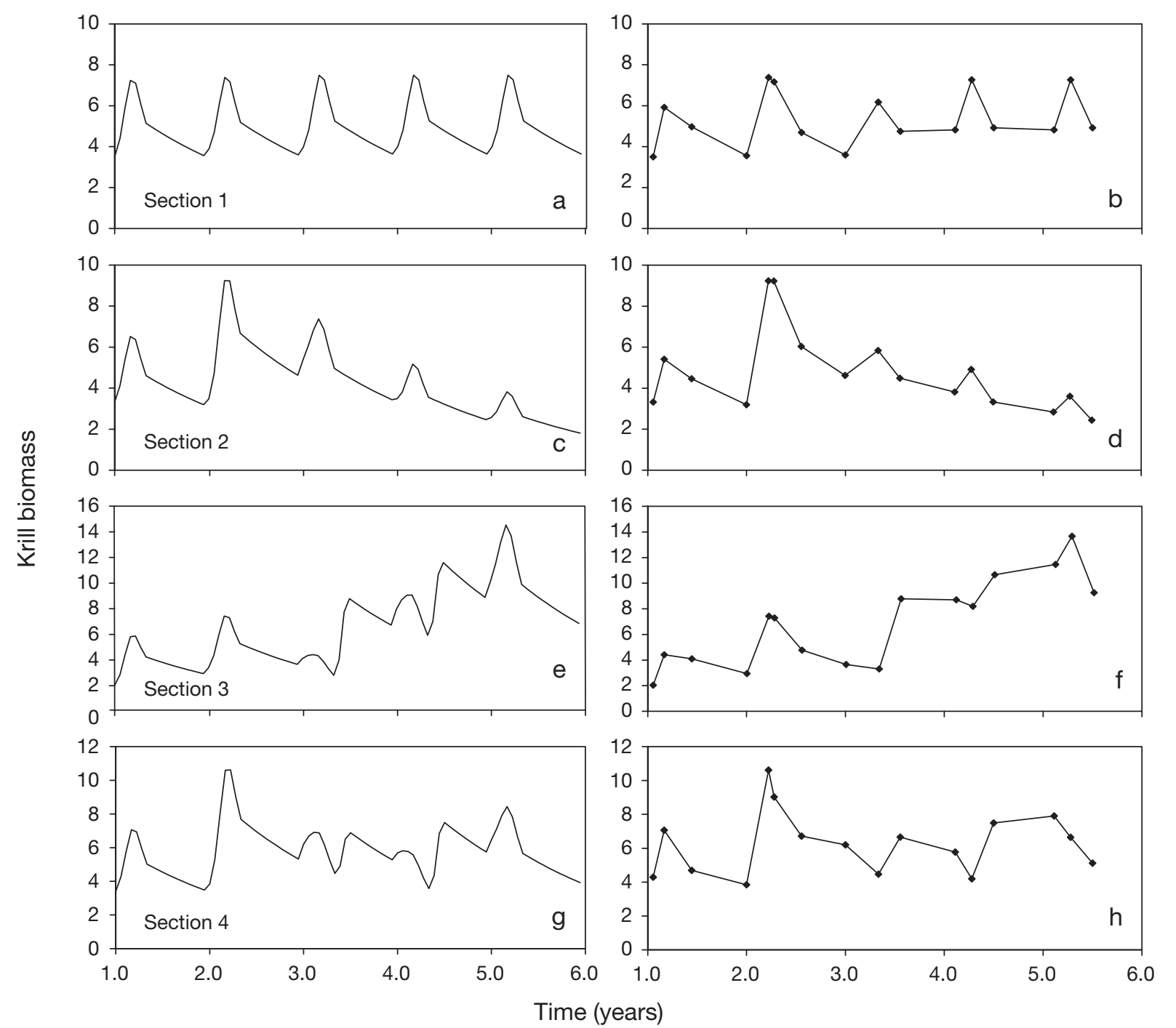

Fig. 2. Krill density ( $a, c$, e and g) and resulting simulated cruise time-series (b, d, f and h) for each of 4 scenarios of recruitment magnitude and timing

summer, the first arising from in situ seasonal growth followed by another associated with the late recruitment of krill into the population (Fig. 2e). In this scenario, delaying recruitment exposes relatively fewer krill to the high-mortality period and hence there is a long-term increase in biomass (Fig. 2e). In the simulated survey time-series this bimodality appears as a pattern of low-low-high biomass (Fig. 2f). In Scenario 4 there was a highly variable pattern with the highest biomass in Year 2 and bimodality apparent in the 2 years in which recruitment was late (Fig. 2g). In the simulated survey time-series, Years 1, 2 and 5 showed a pattern of low-high-low biomass whereas Years 3 and 4 showed a pattern of low-low(er)-high (Fig. 2h).

The correlation between the empirical data and the simulated survey series indicated that only for Scenar- ios 2 and 4 were there significant correlations (Scenario 2: $r_{10}=0.546, \mathrm{p}<0.05$; Scenario 4: $r_{10}=0.608, \mathrm{p}<$ 0.05 ; Table 4). The greatest deviation between the empirical and the simulated survey time-series occurs in 2003 (Fig. 3). However, in Fig. 3 it is apparent that there is a strong signal of bimodality in 2003 and 2004

Table 4. Correlation between empirical and simulated series of krill density estimates for different scenarios of recruitment magnitude and timing

\begin{tabular}{|lcc|}
\hline Scenario & $\mathrm{r}$ & $\mathrm{p}$ \\
\hline 1 & 0.473 & 0.066 \\
2 & 0.546 & 0.029 \\
3 & 0.279 & 0.295 \\
4 & 0.608 & 0.012 \\
\hline
\end{tabular}




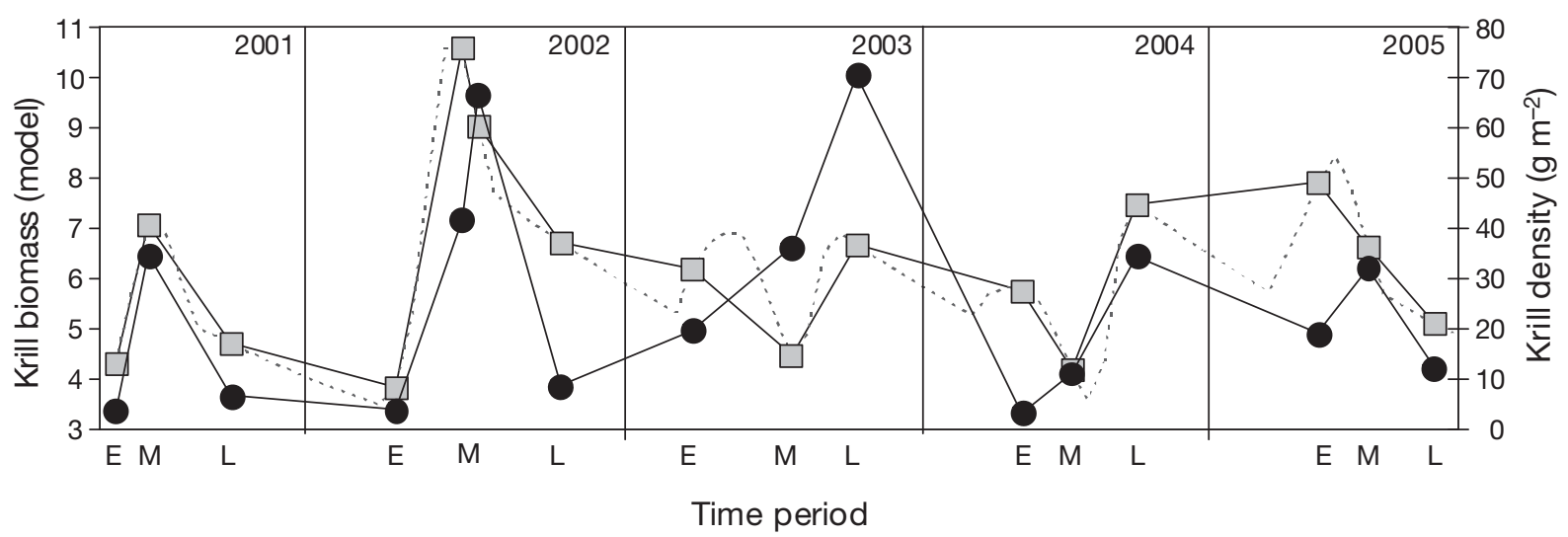

Fig. 3. Simulated and empirical time series of krill density at South Georgia, 2001 to 2005. --- Simulated series; ----- continuous model $_{i} \longrightarrow$ biomass series; E: early; M: middle; L: late

and it is likely that in those years in which a bimodal pattern of krill density occurs, relatively small differences in the timing of sampling may produce quite different patterns in the relative biomass levels between surveys in that year.

\section{DISCUSSION}

The scale of the intra-annual variability was at least as great, if not greater than, the inter-annual variability as measured by mid-season surveys. In the present study we have indicated that this intra-annual variability is consistent with a krill population in which growth is highly seasonal and mortality occurs throughout the year (and is elevated during the period of peak predator demand). The simplest model of intra-annual variation, in which the recruiting year-class always enters the population at the start of the summer and growth occurs in the first $90 \mathrm{~d}$ of the year, produces the lowhigh-low biomass pattern of relative biomass observed in 3 of the 5 years of the present study, and described by Brierley et al. (2002). However, it is clear that there can be considerable deviation from this pattern, especially when recruitment is delayed, when the relative biomass is higher at the end, rather than the middle, of the summer.

In the development of the present analysis it is apparent that considerable uncertainty remains with respect to the variability in the timing of key events in the ecosystem in the South Georgia region as well as in the estimates of krill biomass themselves. While it may be possible to further develop the model presented here to better fit the observed data, doing so would depend upon tuning parameters for which there is a lack of knowledge, not only of those parameter values but also of the potential interactions between them. We feel that the analysis presented here is an important step towards defining a mechanistic understanding of the factors influencing krill abundance at South Georgia. However, we recognise that it would be premature to attempt to derive a mechanistic relationship on the basis of the current model. Similarly, the lack of sufficient information on the uncertainties and covariances associated with the model parameters motivated us to take a scenario-based approach to examine the sensitivity of the model to the effects of varying recruitment timing and magnitude.

The ability to reproduce the observed pattern of krill variability using a simple model with no stock-recruit relationship supports the view of a krill population at South Georgia that can be characterised as a local adult population that is augmented by allochthonous recruitment (Reid et al. 2002). The present study further supports this view of the population in which oceanic transport of juvenile krill into the population has a major influence on recruitment but that the subsequent multi-year dynamics of those krill are governed by local conditions that influence adult growth and mortality. Clearly this does not mean that movement of adult krill does not occur but that it may not be the major factor determining the dynamics of the adult population. The implications for management of this are that although there is no stock-recruit relationship the population is primarily augmented by recruitment rather than a continual flux of adult krill. This means that any assumptions that the temporal separation of the krill fishery from the period of peak predator demand (see Everson \& Goss 1991) would negate competition for resources may be misplaced, especially depending upon the magnitude and timing of recruitment. This also places greater emphasis on the need to acquire more detailed data on the factors affecting krill recruitment into the region, particularly if the scale of the fishery increases, to facilitate effective management of the krill fishery.

The use of predator-derived krill length-frequency distributions to produce relative indices of both re- 
cruitment magnitude and timing provides new insights into the potential consequences of delayed recruitment that may help to explain the deviation from the lowhigh-low biomass profile observed in previous studies. During years when recruitment does not happen until later in the summer, the apparent occurrence of 2 peaks in biomass, the first associated with growth and the latter with the recruitment of new krill into the population, introduces substantial potential for bias into the interpolation of comparable 'annual' indices from point samples. Modelling the process of interannual variability in order to better interpret the results of annual surveys, taken at some point in a cycle of biomass dictated by growth and mortality (and assuming recruitment occurs on Day 1), is greatly confounded by the extent to which there may be variation in the timing of recruitment. This means that in order to understand the temporal scales over which annual krill surveys may be relevant, knowledge of the underlying changes in the krill population is required. Data on such changes could be acquired through the diet of predators (as in the present study) and/or through the use of fixed acoustic moorings (see Saunders et al. 2007).

It is apparent from the work summarised in Murphy et al. (2007a) that large-scale processes, particularly involving sea-ice, play an important role in the interannual variability in the level of krill recruitment at South Georgia and that this has widespread and profound consequences, particularly for dependent species such as penguins and seals (Forcada et al. 2005, Murphy et al. 2007b). These studies have predominantly considered the consequences of the relative magnitude of krill recruitment events on dependent species and have not considered the additional potential consequences of changes in the timing of such events. Clearly, where recruitment happens later in the summer, such that the peak of krill abundance might not coincide with the peak in demand, this may have serious impact on reproductive performance of these species.

Where the factors that dictate the chronology of key life-cycle events of predators and the seasonal dynamics of prey are different, this can lead to a mismatch in the coupling of predators and prey. This mismatch phenomenon has been studied in a range of predatorprey situations (Stenseth \& Mysterud 2002, Durant et al. 2007) and is most pronounced where there is the potential for climate change to introduce differential changes in the phenology of predators and their prey. Such a mismatch may be particularly important in high-latitude systems for those species that are dependent upon ice-free terrestrial habitats for breeding sites. For these species the cues that initiate breeding may be largely influenced by photoperiod, meaning that changes in periods of peak prey abundance brought about by climatic changes may introduce significant mismatches.

Climate change in the SW Atlantic region of the Antarctic has been associated with a reduction in sea-ice as well as an increase in sea temperatures (Vaughan et al. 2003, Meredith \& King 2005). Based on the empirical relationship between sea surface temperature, seaice and krill population size, Murphy et al. (2007a) suggested that there could be $>95 \%$ decline in the krill population at South Georgia over the next $50 \mathrm{yr}$. Clearly this would have profound effects on the populations of the range of krill-dependent species of penguins, seals and whales that characterise the region. The model used by Murphy et al. (2007a) considered the relative magnitude of krill recruitment into the South Georgia region; however, introducing the additional 'risk' of a temporal mismatch between the peak abundance of krill and the demand from predators may produce much more rapid consequences for the populations of those species. These consequences may well be species-specific, with different species showing differing responses; thus detection of the effects of changes in krill abundance may be reflected in changes in the relative differences between species as well as in overall response detected in a multi-species monitoring programme (Murphy et al. 1988, Reid et al. 2005).

Given the relatively short time-series and the complexity of the interactions between krill and sea-ice it is not possible to determine the mechanistic link between sea-ice extent and duration (relative to South Georgia) and the timing of recruitment observed in the present study. Nevertheless, as Thorpe et al. (2007) have shown, sea-ice may potentially have a very strong influence on the timing (as well as the magnitude) of krill recruitment at South Georgia. Therefore, as both the extent and duration of sea-ice respond to regional climate change, in ways that we cannot currently predict, the potential for rapid, non-linear changes in krill and its dependent species must be an important consideration. That the South Georgia region may shift to a non-krill-based ecosystem in less than half a century (Murphy et al. 2007a) should be a cause for concern; that the effects on the ecosystem may be much more rapid places a very strong emphasis on the need to understand the causes and consequences of variation in both the timing and magnitude of krill recruitment to South Georgia.

The analysis presented here represents a major advance in our understanding of the causes of variability in the krill population at South Georgia. The present analysis has indicated that high-resolution data on the sub-annual changes in krill abundance and size structure can provide a step-change in our understanding of 
the mechanisms underlying krill population dynamics in the region. While it is a tautology to suggest that more data is required to manage a fishery, the conclusion of the present study is that with sufficient investment in high-resolution data on krill recruitment, it should be possible to provide the type of prediction of future krill population levels required for effective, sustainable fisheries management.

Acknowledgements. We thank all of those scientists working on Bird Island and aboard the 'James Clark Ross' who have contributed invaluable data to the present study. We are also grateful to 2 anonymous reviewers for their helpful comments that did much to improve the manuscript.

The opinions expressed here are those of the authors and should not be taken to reflect the official view of the Commission for the Conservation of Antarctic Marine Living Resources.

\section{LITERATURE CITED}

Atkinson A, Siegel V, Pakhomov E, Rothery P (2004) Longterm decline in krill stock and increase in salps within the Southern Ocean. Nature 432:100-103

Boyd IL, Staniland IJ, Martin AR (2002) Distribution of foraging by female Antarctic fur seals. Mar Ecol Prog Ser 242: 285-294

Brierley AS, Watkins JL, Goss C, Wilkinson MT, Everson I (1999) Acoustic estimates of krill density at South Georgia, 1981 to1998. CCAMLR Sci 6:47-57

Brierley AS, Goss C, Grant SA, Watkins JL and others (2002) Significant intra-annual variability in krill distribution and abundance at South Georgia revealed by multiple acoustic surveys during 2000/01. CCAMLR Sci 9:71-82

> Chavez FP, Ryan J, Lluch-Cota SE, Niquen M (2003) From anchovies to sardines and back: multidecadal change in the Pacific Ocean. Science 299:217-221

Croxall JP, McCann TS, Prince PA, Rothery P (1988) Reproductive performance of seabirds and seals at South Georgia and Signy Island, South Orkney Islands, 1976-1987: implications for Southern Ocean monitoring studies. In: Sahrhage D (ed) Antarctic Ocean and resources variability. Springer-Verlag, Berlin, p 261-285

> Croxall JP, Reid K, Prince PA (1999) Diet, provisioning and productivity responses of marine predators to differences in availability of Antarctic krill. Mar Ecol Prog Ser 177: 115-131

Durant JM, Hjermann DO, Ottersen G, Stenseth NC (2007) Climate and the match or mismatch between predator requirements and resource availability. Clim Res 33: 271-283

Everson I, Goss CM (1991) Krill fishing activity in the Southwest Atlantic. Antarct Sci 3:351-358

Foote KG, Knudsen HP, Vestnes G, MacLennan DN, Simmonds EJ (1987) Calibration of acoustic instruments for fish density estimation: a practical guide. ICES Coop Res Rep 144:1-69

- Forcada J, Trathan PN, Reid K, Murphy EJ (2005) The effects of global climate variability in pup production of Antarctic fur seals. Ecology 86:2408-2417

Greenberg DA, Dupont F, Lyard FH, Lynch DR, Werner FE (2007) Resolution issues in numerical models of oceanic and coastal circulation. Cont Shelf Res 27:1317-1343
Greene CH, Stanton TK, Wiebe PH, McClatchie S (1991) Acoustic estimates of Antarctic krill. Nature 349:110

Hewitt RP, Demer DA, Emery JH (2003) An 8-year cycle in krill biomass density inferred from acoustic surveys conducted in the vicinity of the South Shetland Islands during the austral summers of 1991-1992 through 2001-2002. Aquat Living Resour 16:205-213

Hewitt RP, Watkins JL, Naganobu M, Sushin V and others (2004) Biomass of Antarctic krill in the Scotia Sea in January/February 2000 and its use in revising an estimate of precautionary yield. Deep-Sea Res II 51:1215-1236

Jolly GM, Hampton I (1990a) A stratified random transect design for acoustic surveys of fish stocks. Can J Fish Aquat Sci 47:1282-1291

Jolly GM, Hampton I (1990b) Some problems in the statistical design and analysis of acoustic surveys to assess fish biomass. Rapp P-V Reùn Cons Int Explor Mer 189:415-420

- Leaper R, Cooke J, Trathan PN, Reid K, Rowntree V, Payne $\mathrm{R}$ (2006) Global climate drives southern right whale (Eubalaena australis) population dynamics. Biol Lett 2: 289-292

> Meredith MP, King JC (2005) Rapid climate change in the ocean west of the Antarctic Peninsula during the second half of the 20th century. Geophys Res Lett 32:L19604 doi:10.1029/2005GL024042

Murphy EJ, Reid K (2001) Modelling Southern Ocean krill population dynamics: biological processes generating fluctuations in the South Georgia ecosystem. Mar Ecol Prog Ser 217:175-189

Murphy EJ, Morris DJ, Watkins JL, Priddle J (1988) Scales of interaction between Antarctic krill and the environment. In: Sahrhage D (ed) Antarctic Ocean and resources variability. Springer-Verlag, Berlin, p 120-130

> Murphy EJ, Watkins JL, Meredith MP, Ward P, Trathan PN, Thorpe SE (2004) Southern Antarctic Circumpolar Current Front to the northeast of South Georgia: horizontal advection of krill and its role in the ecosystem. J Geophys Res Oceans 109:C01029

> Murphy EJ, Trathan PN, Watkins JL, Reid K and others (2007a) Climatically driven fluctuations in Southern Ocean ecosystems. Proc Biol Sci 274:3057-3067

Murphy EJ, Watkins JL, Trathan PN, Reid K and others (2007b) Spatial and temporal operation of the Scotia Sea ecosystem: a review of large-scale links in a krill centred food web. Philos Trans R Soc Lond B 362:113-148

> Nicol S (2006) Krill, currents, and sea ice: Euphausia superba and its changing environment. Bioscience 56:111-120

Reid K, Watkins JL, Croxall JP, Murphy EJ (1999) Krill population dynamics at South Georgia 1991-1997, based on data from predators and nets. Mar Ecol Prog Ser 177:103-114

Reid K (2001) Growth of Antarctic krill Euphausia superba at South Georgia. Mar Biol 138:57-62

Reid K, Murphy EJ, Loeb V, Hewitt RP (2002) Krill population dynamics in the Scotia Sea: variability in growth and mortality within a single population. J Mar Syst 36:1-10

Reid K, Croxall JP, Briggs DR, Murphy EJ (2005) Antarctic ecosystem monitoring: quantifying the response of ecosystem indicators to variability in Antarctic krill. ICES J Mar Sci 62:366-373

Reiss CS, Cossio AM, Loeb V, Demer DA (2008) Variations in the biomass of Antarctic krill (Euphausia superba) around the South Shetland Islands, 1996-2006. ICES J Mar Sci 65:497-508

Saunders RA, Brierley AS, Watkins JL, Reid K, Murphy EJ, Enderlein P, Bone DG (2007) Intra-annual variability in the density of Antarctic krill (Euphausia superba) at South Georgia, 2002-2005: within-year variation provides a new 
framework for interpreting previous 'annual' estimates of krill density. CCAMLR Sci 14:27-41

Stenseth NC, Mysterud A (2002) Climate, changing phenology, and other life history traits: nonlinearity and matchmismatch to the environment. Proc Natl Acad Sci USA 99:13379-13381

Tarling GA, Cuzin-Roudy J, Thorpe SE, Shreeve RS, Ward P, Murphy EJ (2007) Recruitment of Antarctic krill Euphausia superba in the South Georgia region: adult fecundity and the fate of larvae. Mar Ecol Prog Ser 331:161-179

Editorial responsibility: Andrew Brierley,

St. Andrews, UK
Thorpe SE, Murphy EJ, Watkins JL (2007) Circumpolar connections between Antarctic krill (Euphausia superba Dana) populations: investigating the roles of ocean and sea ice transport. Deep-Sea Res I 54:792-810

Vaughan DG, Marshall GJ, Connolley WM, Parkinson C and others (2003) Recent rapid regional climate warming on the Antarctic Peninsula. Clim Change 60:243-274

Watkins JL, Brierley AS (2002) Verification of acoustic techniques used to identify Antarctic krill. ICES J Mar Sci 59: 1326-1336

Submitted: September 11, 2008; Accepted: October 6, 2009 Proofs received from author(s): January 22, 2010 